\title{
The Social Network Generation And Implications For Human Resource Managers
}

Connie Browning Budden, Southeastern Louisiana University, USA

Michael Craig Budden, Southeastern Louisiana University, USA

\begin{abstract}
Tens of millions use social networks on a regular basis. Social networks encourage the sharing of information, photos, videos, accomplishments, and experiences via the internet. Their widespread and increasing usage especially among young people has been well-documented. Individuals who have started such networks have become wealthy as sites have gone public. Businesses are increasingly becoming involved in the networks as they realize the large following that the networks have generated and the fact that such networks can be sources of useful information on which to base decisions. Social networks and individual members who utilize such networks are becoming increasingly aware that there are advantages and disadvantages to such usage. Network users need to be aware that postings on these networks are being scrutinized in ways those posting the information had not imagined when they signed on. Firms increasingly are investigating applicant users through the networks. Indeed, human resource managers have more tools and investigation avenues at their disposal now than ever before.
\end{abstract}

Keywords: Human resources, social networks, management

\section{INTRODUCTION}

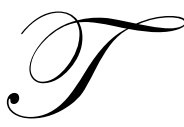

oday, millions of young people and especially college students are making significant use of social networks via the internet. Social network websites including MySpace and Facebook, and a litany of others that are not so well-known are changing the social communications arena.

As studies have shown, the recent use of social websites is driving much of the current social interaction among young people. Marketers and businesses have taken notice and have created a variety of social network sites that are tied to products and brands, and that coincidentally promote the product/brand use. Other businesses are accessing social websites in order to obtain market information, and even information on individuals who have made application for employment.

Social websites provide users with a medium through which social interactions, erroneously believed by many to be private, can take place. However, as some users are discovering, social websites are not private - not by a long stretch. Indeed, as savvy employers are discovering, social websites can provide them with revealing glimpses into the lives of potential employees. While such internet scrutiny by employers of the social interaction of potential employees raises concerns for some, it wins accolades from others for its ability to provide additional insights and provide for better due diligence in the human resources hiring process.

\section{BACKGROUND OF SOCIAL WEBSITES}

The internet was initially developed and its use restricted to scientific research by the US Department of Defense (Cheung \& Huang, 2005). Since its widespread adoption, the internet has impacted the lives of people from all walks of life, including impacts on business, shopping and social activities (Cheung \& Huang, 2005). Internet social activities have presented marketers with challenges as well as opportunities to reach specific target markets. 
Facebook exploded on the social network scene three years ago and was originally viewed as a networking site limited to college students. The site was opened to high school students last September and will soon be available to anyone with a valid e-mail address (Kornblum, 2006). In 2006, Facebook was serving as many as 7.5 million registered users and was seventh among the more accessed websites in the U.S. according to Cuesta (2006). Facebook and the other major social site, MySpace, are the two most popular social sites for today's college students (Cuesta, 2006). Amazingly, MySpace's membership stood at more than 40 million at the end of 2005 (Hempel \& Lehman, 2005).

A study conducted by the Harris Poll for Northwestern Mutual indicated that the college class of 2001 has a $100 \%$ usage of the internet (The Futurist, 2001). Usage among this group has nearly doubled from 6 hours a week on first entering college to 11 hours a week by the end of 2001 (Futurist, 2001). Budden, Anthony, Budden \& Jones (2007) found students at one university were spending 9.6 hours per week on the internet which is not too different from the study cited by The Futurist.

Students in Budden, et. al (2007) were found to spend large amounts of time using various media during their daily routines. Their use of the internet including e-mail, classroom assignments including research, and other uses, excluding time spent on MySpace, Facebook and other social sites total more than 6.8 hours per week. Throw in the use of social websites, and the use of the internet by college students is staggering.

Some are concerned that this increasing use of the internet which by its nature is a solitary activity may be detrimental to total social development. However, surprisingly, three-fourths of students in one study felt that usage of the internet brought them closer to people (Weiskirich \& Murphy 2004). Weiskirich \& Murphy (2004) found that the socializing potential of the internet is increasing with the expanding of connectivity and interactivity by students. Internet usage for students at public universities was significantly higher than that of students attending private universities (Davis, Smith, Rodrigue, Pulvers, 1999). Davis et al also found that men at public universities spent more time on the internet than their counterparts at private universities.

\section{HUMAN RESOURCE IMPLICATIONS}

Internet usage for college students has increased but social networking online has been growing at an accelerating pace. This increasing use of the internet for socialization has major implications for managers and human resource departments. Social websites are increasingly being used in a variety of ways by job seekers and potential employers alike. Recent college graduates are using skills developed by using social networks such as Facebook and MySpace to improve their resume, while current students are using the website to screen potential roommates. Professionals are using a number of different social websites to expand their professional networks. Many companies are using social websites to improve recruitment of potential employees. Also, companies are using these websites to conduct background checks on potential job applicants.

College graduates looking for employment are finding that proficiency in using social networks may be considered a marketable skill. In a recent article Mattioli (2007) suggests that when applying for a position graduates should emphasize their ability to connect with customers through new technologies rather than their proficiency in using social networks.

Company recruiters are using Facebook, MySpace and LinkedIn when searching for new employees (Athavaley, 2007). Companies have found that using these popular websites saves money and time that would have been spent on face-to-face interviews in the past. Professional network sites such as LinkedIn Corp and Jobsters make it easy for employers to get information from people who have worked with or personally know potential job candidates. Recruiters also look at Facebook and MySpace for mutual connections that can provide information on the applicant. These sites are often used for entry and mid level job applicants but also for professionals and CEO's (Athavaley, 2007). 
Hoffman (2007) reports on a recent survey by Computer Vital Signs, that $4 \%$ of IT professionals used blogs or social networking sites to reach potential IT candidates. Professional networking sites such as LinkIn were used by $15 \%$ of IT companies for recruitment. Still, $52 \%$ of the companies reported not using web 2.0 tools.

Another use recruiters for businesses and colleges are finding for the social and professional networks is to perform background checks on potential employees. In the past many companies used Google and Yahoo to perform these background checks but recently Facebook, MySpace, Xanga and Friendster are being utilized in this regard (Finder, 2006). These organizations are looking for "red flags" which might indicate that the potential student or employee might not fit into organizational cultures as expected. Organizations often gain access to these websites by asking a college student working for the organization to perform the background check. Thus, while some college students think only other students have access to their postings, they are finding that such postings are often times ending up on the desks of potential employers.

Many professionals are finding the need to forge new and expanded professional ties (Kadlec, 2007). Two of the most popular sites are Facebook and LinkedIn. A number of other business networks are available including Ryze and Doostang. Networks can help professionals stay abreast of business opportunities and show employers how informed they are of the latest technology. When using business networks professionals should link to people they would be willing to help and who they feel would be willing to help them. Also, professionals should keep their profiles professional and avoid personal disclosures. Indeed, avoiding personal disclosures is arguably important for all users of the internet.

Students and their parents are also jumping on the background checking abilities of social networks. For instance, parents and students are using social networks including Facebook to conduct research on potential roommates before schools start (Millar, 2007). Students and their parents are able to get profiles on the potential roommate's gender, sexual orientation, politics, religion, interests and photos. If there is a potential for problems or conflicts a student is able to request a reassignment before the academic year begins. This ability to investigate potential roommates before a school term begins is a boon to those living in university housing and may lead to better placements and their resulting relationships.

\section{SUMMARY}

Internet-based social websites are entrenched in the lexicon of today's young generation. The heavy and growing use of social websites allows students to stay in touch, share information, share experiences and communicate with many via the internet. There are no borders nor are there limits to the ability of website members to share and communicate with their friends.

Specific Implications for human resource managers include:

- Background information on potential employees that reveal character may be available through online social networks

- $\quad$ Social networks may provide sources of potential applicants that meet company expectations

- $\quad$ Social networks may provide a ready recruiting source for potential employers

- $\quad$ Social networks can be used as a recommendation source for applicants

- $\quad$ Social networks can provide evidence of internet savvy and knowledge by users who may be applicants

- $\quad$ Professionals may and do take advantage of social networks in a manner that may prove beneficial to their firms

However, students need to be aware that any information, videos, or photos posted on the internet via a social website may be viewable by others to whom the information was not intended. Needless to say, the ability of people intent on doing harm to individuals whose information is shared on the internet are a concern for authorities, parents and hopefully all who use such sites. 
Employers and especially human resource managers are increasingly looking to the internet to conduct background checks on potential employees. The ability of human resource managers to access information on applicants has never been easier. At the speed of the internet, information is often available that may make or break an application. Students looking for employment need to be aware of the potential impact of their social website postings by employers.

\section{AUTHOR INFORMATION}

Connie B. Budden is an instructor of Management at Southeastern Louisiana University. Her research interests include human resource development, leadership and international management.

Michael C. Budden is the Mayfield Professor of Marketing at Southeastern Louisiana University. His research interests include commercial law, international marketing and business education.

\section{REFERENCES}

1. Athavaley, A.(2007). Job references you can't control. The Wall Street Journal, (Eastern edition), D.1.

2. Budden, C.B., Anthony, J. F., Budden, M.C. and Jones, M.A. (2007, $3^{\text {rd }}$ Quarter). Managing the evolution of a revolution: Marketing implications of internet media usage among college students. College Teaching Methods and Styles Journal, 3(3), 5-10.

3. Cheung, W., and Huang, W. (2005). Proposing a framework to assess internet usage in university education: an empirical investigation from a student's perspective. British Journal of Educational Technology, 36(2), 237-253.

4. Cuesta, C. (2006). Students love social-networking sites-and so do employers. http://www.Foxnews.com/story/0,2933,208175,00.html.

5. Davis, S., Smith, B., Rodigue, K., Pulvers, K. (1999). An examinination of internet usage on two college campuses. College Student Journal, 33(2), 257-261.

6. Finder, A.(2006). Guess Who's Looking at Your Web Page? New York Times Upfront, 139(2), 16-17.

7. Hempel, J., Lehman, P. (2005). The MySpace generation. Business Week, 3963, 88-93.

8. Hoffman, T.(2007). The Recruit/Retain Shuffle. Computerworld, 41(31), 28-32.

9. Kadlec, D.(2007). You Oughta Be in Facebook. Money, 36(10), 44-44.

10. Kornblum, J. (2006). Facebook will soon be available to everyone. USA Today, 9-11.

11. Millar, E.(2007). A New Use for Facebook. Maclean's, 120(38), 60-60.

12. Mattioli, D.(2007). Hard Sell on 'Soft' Skills Can Pimp a Resume; Experience With Facebook, Class Projects, Juggling Activities Can Impress Employers. The Wall Street Journal. B.6.

13. The Futurist (2001, September-October). The web-connected generation: 9.

14. Weisskirch, R., Murphy, L. (2004). Friends, porn, and punk: sensation seeking in personal relationships, internet activities, and music preference among college students. Adolescence, 39(154), 189-201. 